\title{
Effect of Aerobic Training and Resistance Training on Blood Pressure in Indian: Systematic Review
}

\author{
Sonu Punia ${ }^{1}$, S. Kulandaivelan ${ }^{2}$, Vandana Punia ${ }^{3}$ \\ ${ }^{1,2}$ Assistant Professor, Department of Physiotherapy, GJUS \& T, Hisar \\ ${ }^{3}$ Associate Professor, Academic Staff College, HRDC, GJUS \& T, Hisar
}

\begin{abstract}
Introduction: Hypertension is a public health concern due to its magnitude, risks, difficulty in management, high medical and social costs and severe cardiovascular and renal complications. The number of deaths due to hypertension as primary cause was estimated to be over 7 million in 2002, approximately 13\% of all reported deaths. Hypertensive adults will reach 1.5 billion by 2025; around $30 \%$ of the world population. Hypertension (HTN) is emerging as public health problems in various ethnic groups in the developing countries like India. Prevalence of hypertension has been found to be increasing in epidemic proportions in urban, rural and tribal population of India. Objective: To systematically review and report the articles from India in aerobic and resistance exercise on blood pressure. Methodology: Study was done on February 2016 in Google Scholar using search terms 'Aerobic' AND 'Resistance' AND 'Blood pressure' AND 'India'. 4 articles were identified for this review based on inclusion and exclusion criteria. Results: Studies were at least 6 weeks duration with 60-85\% HRmax of intensity for 30-40 min duration. Total of 130 subjects participated with median of 10 subjects. The results suggest that there was mean reduction of $-5.02 \mathrm{mmHg}$ in $\mathrm{SBP}$ and $-3.142 \mathrm{mmHg}$ in DBP in aerobic training group and also there was reduction of $-3.015 \mathrm{mmHg}$ in $\mathrm{SBP}$ and $-1.415 \mathrm{mmHg}$ in $\mathrm{DBP}$ in resistance training group. Conclusion: The present review conclude that aerobic exercise training reduce the blood pressure more as compared to resistance training in Indians.
\end{abstract}

Keywords: aerobic, resistance, blood pressure

\section{Introduction}

According to the World Health Organization, nontransmissible diseases will be the leading cause of functional disability in the next two decades and, among chronic degenerative conditions, arterial hypertension will be the most important cause. Hypertension is a public health concern due to its magnitude, risks, difficulty in management, high medical and social costs and severe cardiovascular and renal complications. The number of deaths due to hypertension as primary cause was estimated to be over 7 million in 2002, approximately $13 \%$ of all reported deaths. Hypertensive adults will reach 1.5 billion by 2025; around $30 \%$ of the world population. Hypertension (HTN) is emerging as public health problems in various ethnic groups in the developing countries like India. Prevalence of hypertension has been found to be increasing in epidemic proportions in urban, rural and tribal population of India ${ }^{1,2}$.

A study was undertaken to assess the prevalence of hypertension, and knowledge, treatment practice and risk behaviors of tribal men and women $\geq 20$ yr in nine major states in India during 2008-2009 by National Nutrition Monitoring Bureau (NNMB). Overall age-standardized prevalence of HTN was 26.3\% (self-reported: 5.5\%; newly detected: 20.8\%). Urban residents of Tamil Nadu, Jharkhand, Chandigarh and Maharashtra (31.5, 28.9, 30.7 and $28.1 \%$ ) had significantly higher prevalence of HTN compared with rural residents (26.2, 21.7, 19.8 and 24.0\%, respectively).Hypertension, elevated blood pressure (BP), is rising at alarming rate in India. Overall prevalence for hypertension in India was $29.8 \%$. Significant differences in hypertension prevalence were noted between rural and urban parts [27.6\% and 33.8\%; and [17.9\% and 40.8\%]. Age, BMI, Waist circumference, Waist to hip ratio, Excessive salt intake, Alcohol and Smoking are identified risk factors in India ${ }^{3,4}$.

High blood pressure (BP) is one of the most important modifiable risk factors for cardiovascular diseases, which accounts for one in every eight deaths worldwide. Total deaths due to cardiovascular diseases were 9.1 million in developing countries and 1.5 million in India. It has been predicted that by 2020, there would be 111 per cent increase in cardiovascular deaths in India. HTN is directly responsible for 57 per cent of all stroke deaths and 24 per cent of all coronary heart diseases (CHD) in India ${ }^{5,6}$

Hypertensive patients usually have low aerobic capacity and strength due to under lying cardiovascular, neurological and renal disorders (Mercedes R.Carnethon 2005) ${ }^{7}$.

Dynamic aerobic endurance exercise involves large muscle groups in dynamic repetitive activities that result in substantial increases in heart rate and energy expenditure. Current thinking varies with respect to the preferred type of physical activity for BP; historically aerobic training has been preferred. Resistance training is activity in which each effort is performed against a specific opposing force generated by resistance and is designed specifically to increase muscular strength, power, and/or endurance. According to the type of muscle contraction, resistance training can be divided into 2 major subgroups: "dynamic" versus "static or isometric" resistance training. Dynamic resistance training involves concentric and/or eccentric contractions of muscles while both the length and the tension of the muscles change. Isometric activity has previously been associated with exaggerated hypertensive responses, but recent work has suggested isometric handgrip activity may become a new tool in the non pharmacological treatment of high $\mathrm{BP}^{8,9}$. 


\section{International Journal of Science and Research (IJSR) \\ ISSN (Online): 2319-7064 \\ Index Copernicus Value (2013): 6.14 | Impact Factor (2015): 6.391}

Previous meta-analyses have examined the effects of aerobic training, dynamic resistance training in isolation on BP, although a meta-analytic comparison of all different exercise modalities, strictly limited to randomize controlled trials and eliminating data from crossover studies, has not been conducted $^{10,11,12,13}$. The aims of this work were to conduct a systematic review and meta-analysis of randomized controlled trials to compare the effects of aerobic training, dynamic resistance training on the magnitude of change in SBP and DBP in Indian populations, examine whether magnitudes of change in SBP and DBP were related to exercise program characteristics, that is, program duration, exercise session duration, exercise intensity, exercise mode, weekly exercise duration, or weekly session frequency.

\section{Methods}

A database of randomized controlled trials on the effect of exercise training on BP is searched. A systematic search was conducted of resistance training, aerobic and combined training for the period January 1, 2016 until February 28, 2016. The search strategy included key words "Aerobic", "Resistance", "Exercise", and "Blood Pressure" and "India" The inclusion criteria for this meta-analysis were as follows:(1) randomized controlled design trials of exercise training for a minimum of 3-4 weeks; (2) participants were adults (age 20-40 years) (3) the study reported before and after mean and SD (or standard error) of resting BP in exercise and control groups or mean change and SD (or standard error) in exercise and control groups; and (4) the study was published in a journal up to February 2016. Any studies not meeting these criteria were excluded.

\section{Results}

The primary outcome measures were changes in resting SBP and DBP. Descriptive data of treatment groups and participants are reported as the mean SD or median and range. Effect sizes for each study group were calculated by subtracting the pre exercise value from the post exercise value (post-pre).

Chaudhary S.et $\mathrm{al}^{10} 2010$ investigated the effect of Aerobic and Resistance training on cardiovascular fitness in 20 obese sedentary females (35-45 years) for 6 weeks. Resistance Training protocol consisting with Intensity of 4 sets of 10 repetitions and frequency was 3 times/week. Training started with 10 lifts with $50 \%$ of $10 \mathrm{RM}$, then $75 \%$ of $10 \mathrm{RM}$, and progressed to $100 \%$ of $10 \mathrm{RM}$. Regular aerobic training reduced SBP from $128.10 \pm 4.954 \mathrm{mmHg}$ to $124.20 \pm 2.820$ $\mathrm{mmHg}$ and DBP from $85.00 \pm 3.265 \mathrm{mmHg}$ to $81.80 \pm 3.119$ $\mathrm{mmHg}$. There was significant reduction in resting blood pressure (mean SBP $-3.9 \pm 2.134 \mathrm{mmHg}$ and DBP $-3.2 \pm 0.146$ $\mathrm{mmHg}$ ). Aerobic Training protocol consisting of 30 minute duration at $60-70 \%$ HRmax and frequency was 3 times/week. Regular aerobic training reduced SBP from $128.10 \pm 4.954 \mathrm{mmHg}$ to $124.20 \pm 2.820 \mathrm{mmHg}$ and DBP from $85.00 \pm 3.265 \mathrm{mmHg}$ to $81.80 \pm 3.119 \mathrm{mmHg}$. There was significant reduction in resting blood pressure (mean SBP $3.9 \pm 2.134 \mathrm{mmHg}$ and DBP $-3.2 \pm 0.146 \mathrm{mmHg}$ ).

Purvi K.Changela ${ }^{11} 2013$ compared the effect of Aerobic and resistance training on cardiovascular fitness in 10 young obese sedentary females (19-25 years). Resistance training was given for alternate days for 6 weeks with Intensity of 4 sets of 10 repetitions. Training was started with 10 lifts with $50 \%$ of $10 \mathrm{RM}$, then $75 \%$ of $10 \mathrm{RM}$, and progressed to $100 \%$ of 10RM. Results showed SBP reduced from $131.70 \pm 4.667$ to $127.20 \pm 3.190 \mathrm{mmHg}$ and DBP reduced from $83.00 \pm 2.160$ to $82.60 \pm 1.349 \mathrm{mmHg}$ and significant mean difference in SBP $(-3.73 \pm 0.15 \mathrm{mmHg})$ and DBP $(-1.73 \pm 0.49 \mathrm{mmHg})$. Aerobic training was given for 3 days a week at $50-75 \%$ MHR. Training given for 40 minutes duration included warm up and cool down time for 2 months. Results showed SBP reduced from $131.70 \pm 4.083$ to $123.70 \pm 2.540 \mathrm{mmHg}$ and DBP reduced from $86.20 \pm 2.820$ to $80.70 \pm 2.750 \mathrm{mmHg}$ and significant mean difference in SBP $(-8.0 \pm 1.54 \mathrm{mmHg})$ and DBP (-5.5 $\pm 0.07 \mathrm{mmHg})$.

Patel H.et al $^{12} 2014$ investigated the effect of aerobic training and resistance training on 60 hypertensive patients (30-55 Years). Training given for 30 minutes duration included warm up and cool down time for 6 weeks. Results showed mean difference was $-1.60 \pm 0.503 \mathrm{mmHg}$ for SBP and $1.80 \pm 0.410 \mathrm{mmHg}$ for DBP after 6 weeks. Training given for 30 minutes duration included warm up and cool down time for 6 weeks. Results showed mean difference was $3.35 \pm .933 \mathrm{mmHg}$ for SBP and $-2.00 \pm .649 \mathrm{mmHg}$ for DBP after 6 weeks training.

Jaiswal et $\mathrm{al}^{13} 2015$ evaluated the effect of Interval and Circuit training on blood pressure, heart rate and rate of perceived exertion in individuals with 30 prehypertensive subjects (20-40 years). Resistance exercise was given 30 minutes with intensity of $60 \%$ to $80 \%$ of 1 RM for 5 days in a week for 6 weeks. Regular resistance training reduced SBP from $128.26 \pm 2.91$ to $124.53 \pm 3.06 \mathrm{mmHg}$ and DBP reduced from $81.73 \pm 2.12$ to $80.00 \pm 2.61 \mathrm{mmHg}$. Author showed mean difference of SBP $(-3.73 \pm 0.15)$ and DBP $(-1.73 \pm 0.49)$. Aerobic Exercise was 40 minutes on a treadmill with intensity alternating between 50\% (2 min) and 80\%(1 min) of Reserve Heart Rate for 5 days in a week for 6 weeks. Regular aerobic training reduced SBP from 129.46 \pm 2.87 $\mathrm{mmHg}$ to $124.6 \pm 1.95 \mathrm{mmHg}$ and DBP from $81.37 \pm 2.37$ $\mathrm{mmHg}$ to $79.86 \pm 2.56 \mathrm{mmHg}$. Author showed mean difference of SBP $(-4.86 \pm 0.91 \mathrm{mmHg})$ and DBP $(-1.87 \pm 0.19$ $\mathrm{mmHg}$ ) 


\section{International Journal of Science and Research (IJSR) \\ ISSN (Online): 2319-7064}

Index Copernicus Value (2013): 6.14 | Impact Factor (2015): 6.391

Table 1: Summary of Aerobic and Resistance training on blood pressure in Indians

\begin{tabular}{|c|c|c|c|c|c|c|}
\hline $\begin{array}{l}\text { Author } \\
\text { et al }\end{array}$ & $\begin{array}{l}\text { Type of study } \\
\text { Sample Size } \\
\text { Duration }\end{array}$ & Pre SBP & Post SBP & Pre DBP & Post DBP & $\begin{array}{l}\text { Mean Difference } \\
(M D) \text { in } \mathrm{mmHg}\end{array}$ \\
\hline Chaudhary S.et al $^{10}$ & $\begin{array}{c}\text { Experimental } \\
\text { study(35-45 years) } \\
\text { Control }=10 \\
\text { AT }=10 \\
\text { RT }=10\end{array}$ & $\begin{array}{c}\mathrm{AT} \\
128.10 \pm 4.954 \\
\mathrm{RT} \\
129.70 \pm 4.498\end{array}$ & $\begin{array}{c}\mathrm{AT} \\
124.20 \pm 2.820 \\
\mathrm{RT} \\
126.70 \pm 3.713\end{array}$ & $\begin{array}{c}\text { AT } \\
85.00 \pm 3.265 \\
\text { RT } \\
83.70 \pm 2.311\end{array}$ & $\begin{array}{c}\text { AT } \\
81.80 \pm 3.119 \\
\text { RT } \\
83.50 \pm 2.877\end{array}$ & $\begin{array}{c}\text { AT } \\
\text { SBP } \\
-3.9 \pm 2.134 \\
\text { DBP } \\
-3.2 \pm 0.146 \\
\text { RT } \\
\text { SBP } \\
-3.0 \pm 0.785 \\
\text { DBP } \\
-0.4 \pm 0.566\end{array}$ \\
\hline $\begin{array}{c}\text { Purvi K.Changela }^{11} \\
2013\end{array}$ & \begin{tabular}{|c|} 
Experimental \\
study(19-25 years) \\
AT $=10$ \\
RT $=10$
\end{tabular} & $\begin{array}{c}\mathrm{AT} \\
131.70 \pm 4.083 \\
\mathrm{RT} \\
131.70 \pm 4.667\end{array}$ & $\begin{array}{c}\mathrm{AT} \\
123.70 \pm 2.540 \\
\mathrm{RT} \\
127.20 \pm 3.190\end{array}$ & $\begin{array}{c}\text { AT } \\
86.20 \pm 2.820 \\
\text { RT } \\
83.00 \pm 2.160\end{array}$ & $\begin{array}{c}\text { AT } \\
80.70 \pm 2.750 \\
\text { RT } \\
82.60 \pm 1.349\end{array}$ & $\begin{array}{c}\text { AT } \\
\text { SBP } \\
-8.0 \pm 1.54 \\
\text { DBP } \\
-5.5 \pm 0.07 \\
\text { RT } \\
\text { SBP } \\
-3.73 \pm 0.15 \\
\text { DBP } \\
-1.73 \pm 0.49\end{array}$ \\
\hline $\begin{array}{c}\text { Patel H.et al }^{12} \\
2014\end{array}$ & $\begin{array}{c}\text { Experimental } \\
\text { study(30-55 } \\
\text { Years) } \\
\text { AT }=30 \\
\text { RT }=30\end{array}$ & & & & & $\begin{array}{c}\text { AT } \\
\text { SBP } \\
-3.35 \pm .933 \\
\text { DBP } \\
-2.00 \pm .649 \\
\text { RT } \\
\text { SBP } \\
-1.60 \pm 0.503 \\
\text { DBP } \\
-1.80 \pm 0.410\end{array}$ \\
\hline $\begin{array}{c}\text { Jaiswal et al }^{13} \\
2015\end{array}$ & $\begin{array}{c}\text { Experimental } \\
\text { study(20-40 years) } \\
\text { AT }=15 \\
\text { RT }=15\end{array}$ & $\begin{array}{c}\mathrm{AT} \\
129.46 \pm 2.87 \\
\mathrm{RT} \\
128.26 \pm 2.91\end{array}$ & $\begin{array}{c}\mathrm{AT} \\
124.6 \pm 1.95 \\
\mathrm{RT} \\
124.53 \pm 3.06\end{array}$ & $\begin{array}{c}\mathrm{AT} \\
81.37 \pm 2.37 \\
\mathrm{RT} \\
81.73 \pm 2.12\end{array}$ & $\begin{array}{c}\text { AT } \\
79.86 \pm 2.56 \\
\text { RT } \\
80.00 \pm 2.61\end{array}$ & $\begin{array}{c}\text { AT } \\
\text { SBP } \\
-4.86 \pm 0.91 \\
\text { DBP } \\
-1.87 \pm 0.19 \\
\text { RT } \\
\text { SBP } \\
-3.73 \pm 0.15 \\
\text { DBP } \\
-1.73 \pm 0.49\end{array}$ \\
\hline
\end{tabular}

\section{Discussion}

In this present review, we analyzed data from 4 experimental studies assessing the effect of aerobic and resistance training at least 6 weeks duration on blood pressure in Indian adults. The results suggest that there was mean reduction of -5.02 $\mathrm{mmHg}$ in SBP and $-3.142 \mathrm{mmHg}$ in DBP in aerobic training group and also there was reduction of $-3.015 \mathrm{mmHg}$ in SBP and $-1.415 \mathrm{mmHg}$ in DBP in resistance training group. This review revealed that reduction in blood pressure which reached statistical significance in aerobic training group may be because of favorable changes in vascular compliance, which might have occurred after exercise training thus could reduce peripheral resistance ${ }^{10}$. Aerobic training group might have extra benefits due to less myocardial oxygen consumption and load and increasing $\mathrm{HDL}^{14}$. This mean effect is similar to the findings of an earlier Metanalysis focusing on aerobic training and resting blood pressure (Kelley et al 2001, E.M.Murtagh et al 2015) ${ }^{15}$. A previous prospective western study reported that a $2 \mathrm{mmHg}$ reduction in SBP would result in 10\% lower stroke mortality and $7 \%$ lower mortality from ischaemic heart disease or other vascular causes in middle age (prospective studies collaboration, 2002) thus highlighting the clinical significance of even small changes in resting blood pressure $^{16}$. Endurance, dynamic resistance, and isometric resistance training lower SBP and DBP, whereas combined training lowers only $\mathrm{DBP}^{17}$. Data from a small number of isometric resistance training studies suggest this form of training has the potential for the largest reductions in SBP.

\section{Conclusion}

The present review conclude that aerobic exercise training reduce the blood pressure more as compared to resistance training in Indians.

\section{References}

[1] A Bhansali, V K Dhandania, M Deepa, R M Anjana, S R Joshi, P P Joshi, S V Madhu, P V Rao, R Subashini, V Sudha, R Unnikrishnan, A K Das, D K Shukla, T Kaur, V Mohan, R Pradeepa 2015. Prevalence of and risk factors for hypertension in urban and rural India: 


\section{International Journal of Science and Research (IJSR) \\ ISSN (Online): 2319-7064}

Index Copernicus Value (2013): 6.14 | Impact Factor (2015): 6.391

the ICMR-INDIAB study. Journal of Human Hypertension,2015 ;29,: 204-209.

[2] A. Laxmaiah, I.I. Meshram, N. Arlappa, N. Balakrishna, K. Mallikharjuna Rao, Ch Gal Reddy, M. Ravindranath, Sharad Kumar, Hari Kumar \& G.N.V. Brahmam. Socioeconomic \& demographic determinants of hypertension \& knowledge, practices \& risk behaviour of tribals in India. Indian J Med Res ,2015; 141:697-708.

[3] Anchalaa, R., Kannuri, N.K., Pant, H., Khana, H., Franco, O. H., Angelantonio, E. D., Prabhakaran, D. 2014. Hypertension in India: a systematic review and meta-analysis of prevalence, awareness, and control of hypertension. J Hypertens, 32(6):1170-1177.

[4] Devi, P., Rao, M., Sigamani, A., Faruqui, A., Jose, M., Gupta, R., Kerkar, P., Jain, R.K., Joshi, R., Chidambaram, N., Rao, D.S., Thanikachalam, S., Iyengar, S.S., Verghese, K., Mohan, V., Pais, P., Xavier, D. 2013. Prevalence, risk factors and awareness of hypertension in India: a systematic review. Journal of Human Hypertension, 27:281-287.

[5] Gupta R, Guptha S, Sharma KK, Gupta A, Deedwania P. Regional variations in cardiovascular risk factors in India: India Heart Watc. World J Cardiol 2012; 4:112120.

[6] Kaur P, Rao SR, Radhakrishnan E, Rajasekar D, Gupte MD. Prevalence, awareness, treatment, control and risk factors for hypertension in a Rural population in south India. Int J Public Health 2012; 57:87-94.

[7] Chandershekhran B, Arumugam A, Davis F, Kumaran D S, Chandarasharma B,Khundraakpam C, Chanam I, Philipraj Sj, Sanathombi Devi R.Resistance exercise training for hypertension. Cochrane database of systematic reviews 2010, issue 11.

[8] Veronique A. Cornelissen, PhD; Neil A. Smart, PhD. Exercise Training for Blood Pressure: A Systematic Review and Metaanalysis. J Am Heart Assoc. 2013;2:e004473 doi: 10.1161/JAHA.112.004473)

[9] Jasdeep Singh Sandhu, Hardeep Singh Gill, Vidhusi Gupta, Gurmanpreet. Effect of isometric handgrip training on heart rate and arterial blood pressure in normotensive individuals. Scholar journal of applied medical sciences, 2014; 2(6a):2010-2015.

[10] Sarika chaudhry,MSPT, Manpreet Kaur King,MSPT,Jaspal Singh Sindhu,MS,FAIS,FASM. The effect of aerobic versus resistance training on cardiovascular fitness in obese sedentary females. Asian journal of sports medicine, vol1(no 4),2010:177-184.

[11] Purvi K.Changela. A study to compare the effect of aerobic and resistance training on cardiovascular fitness in young obese sedentary females. International journal of health sciences and research, vol.5, issue 10; 2015.

[12] Hasmukh patel, Dhaval Desai, Dhara Desai. A study to evaluate the changes in blood pressure values of hypertensive patients post aerobic and progressive resistance exercise(PRE).International journal of health sciences and research, vol.3, issue 2; 2013.

[13] Amit V.Jaiswal, Atharuddin H.Kazi, Sambhaji B.Gunjal, Prema M.Tawde, Aashirwad A.Mahajan, Subhash M.Khatri. effectiveness of interval training versus circuit training exercises on blood pressure, heart rate and rate of perceived exertion in individual with prehypertension. International journal of health sciences and research, vol.5, issue 10; 2015.
[14] Vanita lal, Anubhav raj, Bharti Bhandari,2014. Chronic effects of aerobic and resistance exercise on cardiometabolic profile in healthy non obese subjects. International journal of clinical and experimental physiology, 2014; vol 1: issue 3.

[15] Kelley G.A.,Kelley K.S.,Tran Z.V.,2001. Walking and resting blood pressure in adults: a meta-analysis. Prev.Med; 33:120-127.

[16] E.M.Murtagh, Linda Nicholas, Mohammed A.Mohammed, Roger Holder, Alan M.Nevill,Marie H.Murphy 2015. The effect of walking on risk factor for cardiovascular disease: an updated systematic review and meta-analysis of randomized control trials. Prev.Med; 72(2015):34-43.

[17] Mengistie Alemayehu Belay, Reddy R.C.and Syam Babu M. The effects of combined aerobic and resistance exercise training on obese adults, northwest Ethiopia. Research journal of recent sciences Vol.2 (1), 59-66, January 2013. 